\title{
LULL(ed) into complacency: a perspective on licenses and stem cell translational science
}

\author{
Mahendra S Rao
}

\begin{abstract}
The US has had a very successful model for facilitating the translation of a basic discovery to a commercial application. The success of the model has hinged on providing clarity on ownership of a discovery, facilitating the licensing process, providing adequate incentive to the inventors, and developing a selfsustaining model for reinvestment. In recent years, technological, political, and regulatory changes have put strains on this model and in some cases have hindered progress rather than facilitated it. This is particularly true for the nascent field of regenerative medicine. To illustrate this, I will describe the contributing practices of several different entities, including universities, repositories, patent trolls, and service providers. It is my hope that the scientific community will be motivated to coordinate efforts against these obstacles to translation.
\end{abstract}

\section{The biotechnology industry in the US}

The biotechnology industry in the US has flourished over the past several decades for a variety of reasons. Perhaps one important reason for this is the way intellectual property has been transferred from inventors to developers for the benefit of the end user. In the US, research is funded largely by the government through its various arms, such as the National Institutes of Health (NIH), the National Science Foundation, the Department of Defense, the Environmental Protection Agency, the National Institute of Standards and Technology, and the US Food and Drug Administration. This effort is supplemented by support from foundations, non-profits, and state agencies.

The transfer of intellectual property has been governed largely by the Bayh-Dole Act of 1980, which specified that the government would fund inventions but not own

Correspondence: mahendra.rao@nih.gov

50 South Drive, Suite 1140, Bethesda, MD 20892, USA them. Inventorship and ownership rights to discoveries would be held by the inventors and the organizations to which they belonged. This extended to Small Business Innovation Research and Small Business Technology Transfer grants awarded by the government to small businesses. Given the pre-eminent role that the government plays in funding research, most other agencies have followed the government's practice of assigning ownership to the inventors and not retaining ownership of funded work.

Realizing that this access to know-how and patents represented an unprecedented opportunity, many universities developed models to leverage the discoveries arising from work funded by the NIH at their institutes. Universities and hospitals such as St Jude, City of Hope, University of Wisconsin-Madison, Harvard, and Stanford set up licensing models that allowed a relatively straightforward transition from invention to commercial application.

Similarly, the medical and biotechnology sector saw an opportunity to obtain novel results and rights to technology that was significantly cheaper than funding the entire research effort and, more often than not, opted to license technology typically at an early stage from universities. The many examples of these successful transfers illustrate that this practice has been an important source of revenue for universities [1].

Some universities and hospitals have gone a step further, using the profits generated from the licensing efforts to fund applied research, worked with industry to obtain research contracts to generate results on behalf of pharmaceutical companies, or set up investment funds to support biotechnology incubators and academiabased spin-offs.

These approaches have led to a thriving biotechnology sector with hubs of activity anchored by major universities and an immensely successful model for taking a basic science discovery from the laboratory to a commercial application. It is my belief that no country has an equivalent model and that this has perhaps 
contributed to the technological lead that the US has enjoyed in the biotechnology sector.

Inventors feel that it is easiest to get their discoveries recognized. Universities recognize their contribution, and funding agencies allow them to own their invention, and since universities support commercialization, an inventor has a choice to set up his own company, license his technology to a small company, or allow the university to manage the discovery in return for an equitable return (generally $30 \%$ ).

\section{Cracks in the system}

Although this model is very successful and serves as an example for other countries in jump-starting innovation in biotechnology, success itself can breed problems. A list of challenges facing stem cell biotechnology companies is summarized in Table 1 [2-6], and a selection of these issues is discussed below.

\section{The irrational exuberance of patenting}

The very success of the model has led universities to take an aggressive stance on patenting, and the number of patents filed has increased dramatically [7]. Technology transfer offices do not have the capacity to monitor all of these patents, bundle them for efficiency, or even ensure that the most relevant claims related to the specific invention or discovery are filed. Rather, a generic set of claims is filed and a somewhat standardized process is used which, given the very nature of the inventive process, guarantees inefficiency.

Most universities have opted to file provisional patents, which for minimal cost allow a year for filing claims and obtaining additional data (based on US patent law) while giving an early priority date. This puts pressure on scientists to develop something or lose the patent and on university technology transfer offices to find that elusive licensing partner willing to incur the large up-front and royalty costs despite the uncertainty associated with such an early stage of technology. Even though the 'first to file' patent system enacted this year will eliminate interference proceedings and bring the US system into harmony with the rest of the world, the provisional patent application will become an even more popular tool for small companies to protect and acquire intellectual property rights.

\section{The costs of patenting and issues with know-how and patents}

The large number of patents also places a cost burden on the industry. Patent costs have soared because the US Patent and Trademark Office often requires a single comprehensive patent to be broken up into multiple independent patents, and there is often the need to file additional patent claims to bolster the narrow claims issued. The large number of claims arises not only from the boilerplate patenting strategy used but also the aggressive rush to patent anything that might be useful at a university.

Patenting now needs to be done worldwide, yet each country examines patents separately and has separate patent filing and maintenance fees. The average cost of successfully prosecuting a patent has soared to upwards of a quarter of a million dollars and is likely to go even higher.

The large number of patents and claims filed and the time period to examination, rejection, or issuance have also resulted in an added burden for lawyers, who have to search to ensure that the claims they license are indeed worthwhile and that they will not be subject to lawsuits or infringement claims later when they have locked into a particular technology.

The nature of patent law brings a potential ironic twist to the proceedings. Patent law requires, on the one hand, that sufficient description be provided, so that anyone reasonably adept in the art can reproduce your results, a logical requirement designed to prevent fanciful claims. Yet on the other hand, only something truly novel can be patented and this novelty can require quite narrow definitions. Such narrow patents can then be very easily bypassed with just small alterations from the patented procedure. In other words, the very process

Table 1 Challenges for stem cell biotechnology companies

\begin{tabular}{ll}
\hline Hindrances to stem cell translation & Consequences \\
\hline $\begin{array}{l}\text { Fractured history of embryonic stem cell } \\
\text { rules }\end{array}$ & A slowed and staggered entry of commercial entities into the field [2,3] \\
$\begin{array}{ll}\text { Lack of government leadership to } \\
\text { develop a consensus }\end{array}$ & $\begin{array}{l}\text { The lack of early federal standards and infrastructure caused states and countries to lead initiatives that } \\
\text { were not coordinated [4]. }\end{array}$ \\
$\begin{array}{ll}\text { Complexity of the therapeutic solutions } \\
\text { proposed }\end{array}$ & $\begin{array}{l}\text { Unlike chemical compounds, manufacturing techniques and regulations for cellular biologics have not } \\
\text { been straightforward and clear [5]. }\end{array}$ \\
$\begin{array}{ll}\text { Technological strategies being used } & \text { The fast pace of technological breakthroughs in the field can render products and processes developed } \\
\text { only a few years earlier less competitive or even obsolete. }\end{array}$ \\
$\begin{array}{l}\text { Lack of expertise with patent laws by } \\
\text { the new players }\end{array}$ \\
\hline
\end{tabular}


designed to protect rights has in some cases endowed an advantage to the competition.

Companies have responded by simply not filing patents and treating some information as know-how or a trade secret. Coke is perhaps the classic example of treating a formula as a trade secret rather than a patent. Most tool and reagent companies likewise will use know-how and trade secrets to protect their media formulations. Although this works for companies, academics have a much harder time as their mandate is to publish and share information, relying solely on their patents for protection. In this scenario, a company can retain an improvement on a media formulation in the public domain as a trade secret, which offers the company a benefit with no corresponding return for the inventor of the basic discovery.

\section{Time to discovery and life of patents}

The issues described above, though common to other fields, have become more acute in the biotechnology field for one very simple reason: time from invention to practice. In the software industry in particular, and in most technological sectors in general, generating a marketable product is much faster than in biotechnology. Part of the reason, of course, stems from issues inherent in working with wetware (biological samples). A much more important driver is perhaps the clinical regulatory process, in that development times are getting longer and longer because of the regulatory process. With development times fast approaching the 20 -year protection time offered by patents, one may enjoy far fewer years under patent, reducing potential returns on an investment. One must either delay filing a patent as long as possible or shorten development cycles; otherwise, the development of a novel drug may not be worthwhile unless it is a blockbuster. Given that universities, on the other hand, are rushing to patent (and the earlier the better), we are reaching a point in which these two groups that had once been well coordinated are now at odds with each other [8].

The common solution is to separate patent licenses into use domains for non-regulated and regulated processes; a novel growth factor, for example, may be licensed for research use to multiple entities for a smaller fee and for clinical use to a single entity for a larger fee. However, this is not a comfortable solution for any of the parties. Of concern is that additional discoveries may hinder their primary use or that discovered adverse effects, though not relevant to the clinical application, may by perception alone hinder the path to the clinic. Many investigators could tell you about the ones that got away - promising new products that had great specificity and relevance, such as growth factors, small molecules, or antibodies, but that were inaccessible for research use because of their development for clinical applications.

\section{Technology cycles and obsolescence}

Another important trend threatening the biotechnology licensing infrastructure that has worked so well in the past is the fact that technology changes are happening very rapidly. Increased process times for both issuing patents and launching products make it very likely that a promising product can be pulled, rendered economically non-viable by the emergence of a next-generation product. Yet attempts to rescue it through modifications would simply brand it a new product, triggering the very same rigorous regulatory process.

\section{The cost of free, or the law of unintended consequences}

Another frequent problem is the unintended consequence of actions taken by government and universities in reaction to some of these issues. Universities have asked for continued free unrestricted use for themselves for patents they would otherwise out-license exclusively. The government has asked for free distribution to the academic community of useful products from its funded efforts. For example, non-profits and the government have funded free distribution of growth factors, cytokine reagents such as antibodies, or primers. Although these and all similar efforts are admirable for their good intentions and often very successful resolution of their primary goal, the unintended consequence relevant for this article is the frequent lack of competitive alternatives to such a 'free' product. It is hard for anyone in a for-profit company to justify efforts on such a reagent, and even harder to fund improvements on an existing reagent. Thus, as soon as the government ceases its funding or subsidies, neither the equivalent product nor an improved version is available to fill the resulting gap. This is also true for patents, as illustrated by the recent shortage of generic antibiotics. With the lack of patents for antibiotics, and corresponding lack of perceived profit to be gained, no one undertook the development of a lowcost alternative.

\section{Patent trolls, or let's pay to make the problem go away}

Collective practices at universities and patent offices and the accompanying financial pressures described above have led to rapid out-licensing. Unfortunately, these licenses then can become a financial burden for smaller companies, given their development timelines. This has created an opportunity for 'patent trolls' to acquire licenses from struggling companies for bargain 'penny on the dollar' prices. With no intent to develop the technology themselves, they use these licenses instead as legal leverage to extract returns from companies that may have had more success. And the potential overlap 
in technology fueling these efforts is often there, given how claims tend to be written (to cover as much as possible) and how an understaffed patent office grants them (restricted into narrow claims) and how a university licenses them (no bundling of patents or claims).

These predatory companies essentially take advantage of the 'pay and they'll go away' attitude, banking on the fact that the cost of litigation for a company is often too high, and stays granted by the courts can be a death knell on not just progress but sometimes the company itself. Yet in truth they are simply exploiting weaknesses in the system which have been known to the community but not fixed. In fact, on occasion, these same companies can successfully bundle patents that then have a larger value than they would otherwise, thus performing an important service. We as a community need to take responsibility for fixing the system before it falls apart.

Indeed, the problems I have mentioned have not gone unrecognized, and several efforts to address some aspects of the problem have been attempted. Academics have suggested a 'patents commons' approach. Industry and government alike have looked at FRAND ('fair, reasonable, and non-discriminatory' policies) rules and access to licenses. The government has threatened 'march-in' rights on the grounds of national necessity. The courts have acknowledged a research-use exemption, and companies themselves have made technology they have developed available at reasonable rates or not enforced patents they own, in the name of goodwill. The success or failure of each individual effort merits a separate review. Our intention has been not to discuss the pros and cons of the solutions but simply to lay out the landscape and, as discussed in the next section, to argue that these problems and the near lack of proposed solutions represent a particularly acute problem for the regenerative medicine field.

\section{Problems are more acute for regenerative medicine}

Some of the reasons we at NIH Center for Regenerative Medicine (CRM) believe the issues are more acute for the regenerative medicine industry are summarized in Table 2 [9-13] and briefly discussed below. Perhaps the most important reason is the speed at which technology is moving and the possibility of being in the clinic in a shorter time period than the average cycle of a smallmolecule drug.

The other important reason stems from the way one expects to use stem cells in regenerative medicine. One will either consider using large panels of cells for screening or use cells as therapy, especially as exemplified by the plans for personalized medicine.

In both cases, the problems mentioned above are amplified, and each of the problems needs to be resolved for not one line but many many lines. In both cases, one starts with a cell that undergoes many manipulations and multiple stages of differentiation which involve sorting, selection, culture manipulation, and modulation of engineering (Figure 1). In other words, multiple sets of techniques are also involved. Each of these technologies has seen recent technological breakthroughs and, with them, an accompanying flurry of patent filings and issuance with the usual potential overlap. Thus, many lines and many steps, in turn, mean many patents held by many different groups, making accumulating a comprehensive portfolio nearly impossible.

So we have interesting scenarios happening today, such as in the embryonic stem cell (ESC) field, where key patents are expiring on ESCs right around the time the first commercial product will be launched by folks (a) who paid significant money for them yet now face competition from others who can compete without such costs, or (b) who face companies that could manufacture in a country where patents were never awarded in the first place, or (c) who have licensed patents in which stem cells are not the end product but rather are used to manufacture unlimited quantities of an end product which may be covered by other patents but not by the ESC patents themselves [14].

In the mesenchymal stem cell (MSC) field, companies have identical or related products in the late stage of

Table $\mathbf{2}$ Challenges for induced pluripotent stem cell use in regenerative medicine

\begin{tabular}{|c|c|}
\hline Category & Considerations \\
\hline Consent & Model consent and donor testing, including possible sourcing from existing tissue banks [9] \\
\hline $\begin{array}{l}\text { Method of induced pluripotent stem } \\
\text { cell generation }\end{array}$ & $\begin{array}{l}\text { Integration-free methods: plasmid and Sendai virus versus two-step integration and excision methods - that } \\
\text { is, STEMCCA (EMD Millipore Corporation, Billerica, MA, USA) - and newer methods being developed [10] }\end{array}$ \\
\hline Patents and licenses & $\begin{array}{l}\text { Freedom to operate versus reach-through claims by companies to enable translation but also provide } \\
\text { financial commercial incentive }[8,11]\end{array}$ \\
\hline Characterization and testing & $\begin{array}{l}\text { Pluripotency, differentiation ability, mycoplasma and viral testing, HLA typing and identity, and large-scale } \\
\text { analysis need to be done in a standardized, efficient, and cost-effective manner. Not all tests are currently } \\
\text { available [12]. }\end{array}$ \\
\hline Distribution & $\begin{array}{l}\text { American Type Culture Collection (Manassas, VA, USA), Coriell Institute (Camden, NJ, USA), Rutgers University } \\
\text { (New Brunswick, NJ, USA), WiCell (Madison, WI, USA), PACT (Production Assistance for Cellular Therapies) } \\
\text { Program, and other biobanking institutions need a financially sustainable model [13]. }\end{array}$ \\
\hline
\end{tabular}




\section{BASIC PROCESS CONSIDERATIONS}

Tissue Sourcing: obtain informed consent

iPSC generation: approval of license (ie. iPS Academia Japan, Inc)

Vectors: use episomal plasmids or integration-free methods

Engineering: use open source TALENs or license technology

Processing differentiated cells: acquire license

Delivery Method: device to inject cells
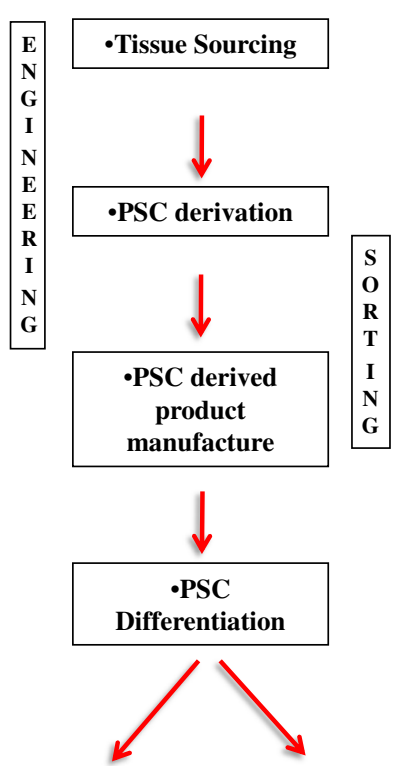

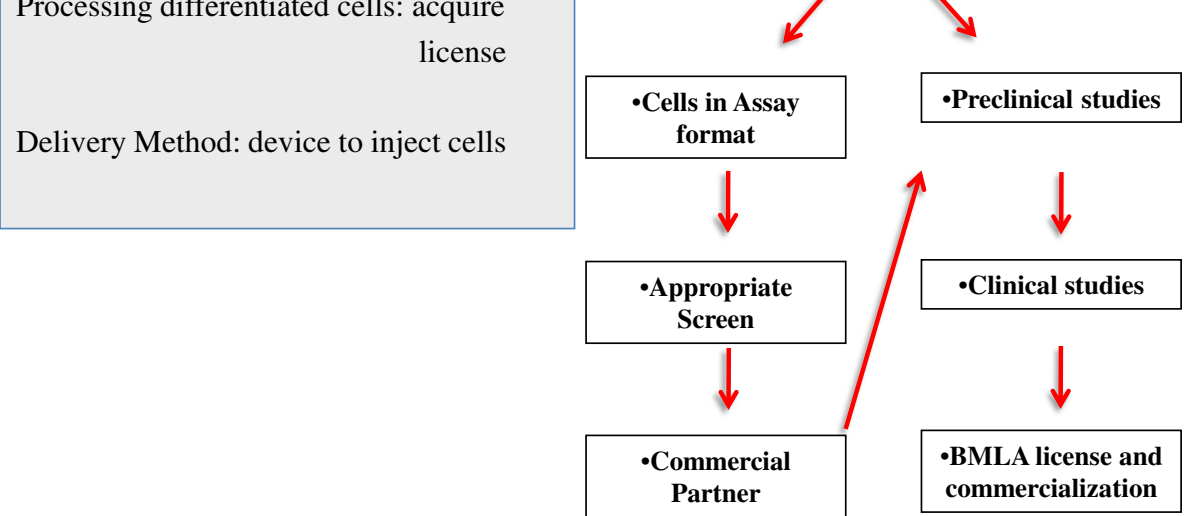

Figure 1 Issues facing stem cell translation. BMLA, biological materials license agreement; iPSC, induced pluripotent stem cell; PSC, pluripotent stem cell; TALEN; transcription activator-like effector nuclease.

clinical trials, at which point it is unlikely that there is any patent protection at all. Indeed, since there is as yet no consensual definition of an MSC, it is even hard to determine whether lawsuits could be successful.

And finally, companies are attempting to use novel technology that may be supplanted by newer technology well before they have moved forward with any commercial product. One potential example of this is homologous recombination, which for therapeutic use was supplanted by gene editing mediated by zinc finger nuclease (ZFN) technology. This ZFN technology was controlled by Sangamo (Richmond, CA, USA) and seemed well on its way to success, only to be threatened in turn by TALEN (transcription activator-like effector nuclease) technology, which appeared to be cheaper, better, and faster. Even TALENs may be supplanted by CRISPR (clustered regularly interspaced short palindromic repeats) before they see routine commercial use [15-17].

Also worth noting is that none of the companies has all the requisite technology it needs to make a cell therapy or engineered cell therapy. None of the companies has had the internal research capacity or the wherewithal to identify, locate and pay for the relevant complementary pieces of technology required. The ESC companies do not have access to differentiated cell patents or to engineering technology. This is likewise true for MSC-based companies. Similarly, Sangamo, a gene engineering company, does not (to our knowledge) have any cell-based patents. Figure 2 illustrates ways that companies can exert control over stem cell translation.

\section{Company strategies to circumvent such problems} Know-how or process control

As discussed above, the use of cells requires multiple steps and, given the cost of the patenting process, one can use know-how rather than patents to protect one's developments. Compared with patents, know-how and trade secrets offer indefinite protection but carry the risk of reverse engineering and independent discovery. However, given that process patents are very narrow and easy 


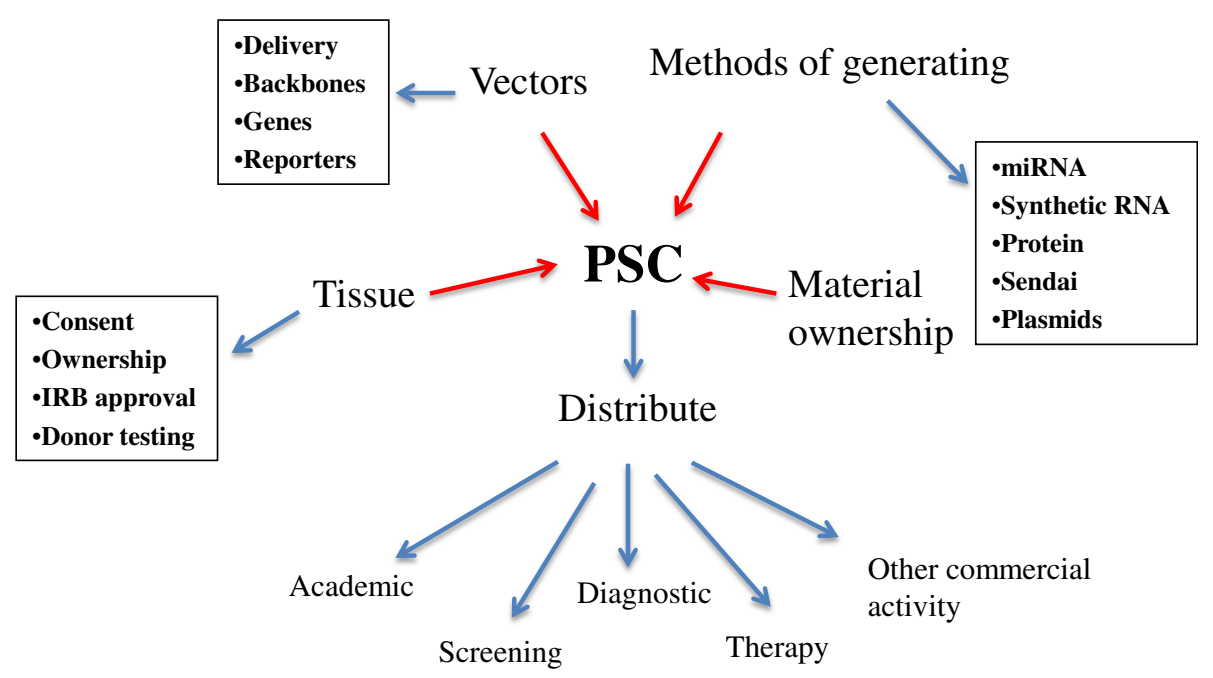

Figure 2 Methods of control. Companies use a variety of strategies to exert control over the various uses of pluripotent stem cells (PSCs). The upstream processes involved in induced-PSC generation can exert more control on downstream activities. It is important to note that no single company controls all the steps. IRB, institutional review board; miRNA, microRNA.

to engineer, trade secrets offer a powerful advantage as black box engineering is much harder than engineering from the published detailed process required by patent law with the sole purpose of bypassing a narrow claim.

Companies have also developed strategies for sharing know-how, making this quite attractive in several cases. Most contract manufacturing organizations (CMOs), for example, will manufacture cells for a client as a service with a clear understanding that the know-how associated with developing the client's process cannot be shared with or used by another company without getting the client's explicit permission or charging a fee on the client's behalf. Companies that use CMOs have developed a level of trust and CMOs have developed a firewall between teams that work on projects, so that accidental leaks can be prevented. Lonza (Basel, Switzerland) and Gibco (a division of Life Technologies, Carlsbad, CA, USA) are examples of CMOs that provide such a service for biologics and cells, and multiple cell therapy or gene therapy organizations have used the same organizations with the confidence that know-how protection is sufficient.

\section{Material ownership and use of license terms to extend the life of the patent}

A solution that several companies have adopted is to apply know-how and process control to cell-based therapy, based on material ownership. They have reasoned that this concept applies because cells can be defined as material, in that individual cells can be clearly identified and distinguished from other functionally identical cells. Thus, even if patents on composition of matter expire, companies can still license their material for use or prevent others from using their material.

MSC-based companies have used this strategy to move forward in the market. MSCs may be functionally identical, may not be patentable, and may not be well described, but one person's MSCs can be clearly distinguished from another's. Likewise, the Wisconsin Alumni Research Foundation can use material licenses for their ESC lines when the patents expire, and they have begun preparing for that by offering their lines for use under what they consider reasonable terms.

This strategy offers companies several benefits. Companies can license their material to maintain its control, with no worry about patent expiration. Licenses can, of course, be extended to derivatives of the material provided that it can be shown that the derivatives contain the original material. So one can reasonably license the use of one's material to make a derivative and can subsequently restrict the use of that derivative.

\section{Monopoly by license and reach-through}

Each of the approaches discussed above, though beneficial to companies, has consequences for the end user. But perhaps the most worrisome has been the aggressive stance taken by some companies. Examples are too numerous to discuss in detail, so I will use just two examples from the cell and engineering world.

DNAVEC, a small company in Tsukuba, Japan, developed a novel technology using RNA virus to make induced pluripotent stem cells (iPSCs). This was a nonintegrating technology well protected by patents and very useful in developing simple and efficient methods to make 
iPSCs. The company saw this as an opportunity and thus developed a license strategy by which a fee was expected for any use either of cells developed using DNAVEC technology or of derivatives from those cells. And since stem cells are immortal, this would play out for anything that was done with these cells and related discoveries.

A similar thing has happened with ZFN technology. Sangamo and Sigma-Aldrich (St Louis, MO, USA), which licensed ZFN technology from Sangamo, have developed a large number of ZFN patents that affect materials engineered using ZFNs, whether the ZFNs were used to engineer cells, or place reporters, or make knockouts. According to Sigma-Aldrich's original license terms, cells modified by using ZFNs cannot be used outside the laboratory or shared even with other investigators, and written permission is required for any use of the cells or their derivatives. Indeed, in conversation, it was suggested that filing patents related to any of these cells should likewise require Sigma-Aldrich's permission.

Such restrictions are commonplace for a given product when it is licensed. We all routinely agree that when buying a product one will not resell it, modify and resell it, or use it in any way other than that outlined by the license. However, it seems somewhat excessive to extend that to secondand third-generation modifications and derivatives when they no longer contain the material or are no longer the cell that was engineered, or to restrict the use of those derivatives. Nevertheless, these companies (and they are just an example) consider this a successful approach, and all of us who sign such licenses confirm its success and encourage others to emulate their success with a similar strategy.

\section{What should an individual investigator do?}

Although these circumvention strategies work for individual companies, they are at best an ad hoc solution or simply a reaction to all the issues we have raised as problems in the patenting, licensing, and university biotechnology nexus. Indeed, going a step further, these solutions are even counterproductive and possibly inhibit the field.

For example, we at the NIH CRM stopped using ZFNs for engineering, as we simply could not afford to have to remake a line made by our collaborator while SigmaAldrich was debating whether we could use it, or wait to deposit cells in a repository, or use them for screening. Likewise, we recommended that colleagues stop using Sendai virus until licensing terms were altered, since we simply could not keep track of distribution of the cells or the differentiated cells that arose from the iPSCs that had been engineered many years in the past. This may not be the best solution for every investigator, but at the very least we would encourage everyone to carefully examine the limited use label licenses that accompany reagents. You may be signing on to more than you intended. In fact, such decisions can ultimately have an effect. Recently after much discussion with universities and other agencies, Sigma has finally revised their license language to allow for the sharing of ZFN-modified cell lines and deposit into repositories. This example showcases how important it is for the stem cell community to keep pushing companies for fair terms of use and how eventually such efforts can succeed. Figure 3 provides examples of pluripotent stem cell modification methods and some of the engineering tools offered by a selection of companies.

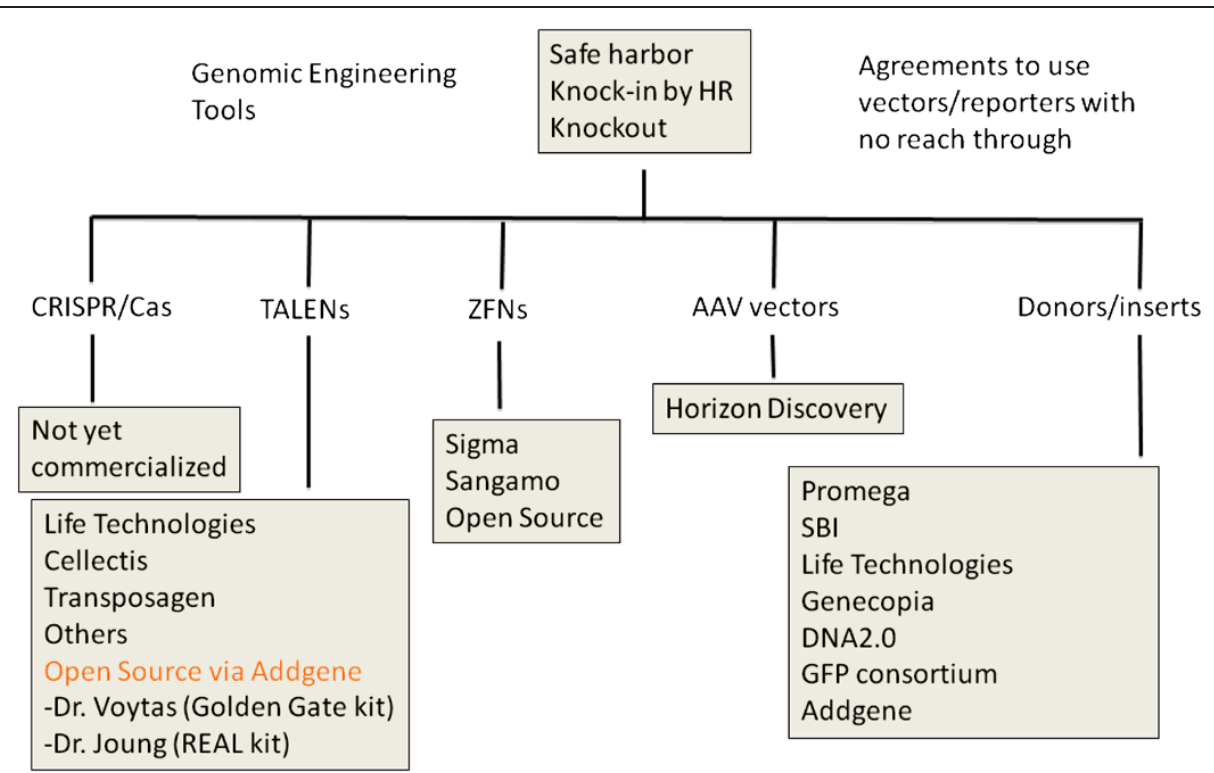

Figure 3 Engineering pluripotent stem cells (PSCs) and freedom to operate. PSC modification methods and some of the engineering tools offered by a selection of companies are shown. AAV, adeno-associated virus; Cas, CRISPR-associated; CRISPR, clustered regularly interspaced short palindromic repeats; HR, homologous recombination; TALEN; transcription activator-like effector nuclease; ZFN, zinc finger nuclease. 
We would also encourage individual investigators to look at alternatives, as we believe alternative models do exist and strong voices can change things. We believe a more elegant set of solutions exist and one should look for strategies to resolve such problems. Perhaps a very good example is PubMed and the open-access strategy in the publishing industry. It has not hampered the commercial efforts but has made publicly funded research widely available at no additional cost to a new investigator and has made research that much easier. Perhaps models such as these could be developed if enough of us made the effort.

One can see another example of success in the sharing of assays developed by commercial entities by the European Chemical Agency's REACH (Registration, Evaluation, Authorisation and Restriction of Chemicals) program. The community effort led to an agreement that assays would be licensed to all entities that participated under a standard agreement and no monopoly would be retained.

The strategy of the non-profit company Addgene (Cambridge, MA, USA) in our own stem cell field is an example of a successful community effort through which vectors can be freely shared by using a standardized template. Addgene works with the UBMTA (uniform biological materials transfer agreement), which the NIH helped to develop and which explicitly defines reachthrough and has been important in enabling widespread dissemination of technology and access to reagents at a reasonable cost. And commercial vendors have found this cost to be in a competitive range for them to offer competing alternatives. We could encourage investigators to use Addgene's services and, more importantly, to contribute to them to enhance the utility of this community effort.

The Canadian stem cell institutes have banded together to try to bundle patents to allow synergy, and we would suggest that university technology transfer offices consider establishing similar common guiding principles of licensing strategy.

We ourselves at the NIH CRM have made an effort to make well-characterized iPSC lines widely available by using a repository model, and we would strongly encourage investigators to consider depositing lines by using a materials transfer agreement that, like the one we have developed, does not reach through to downstream products or restrict the use of the cells to non-commercial purposes. Likewise, we have developed TALENs by using an open-source system that we have made widely available to commercial and non-commercial entities.

\section{Conclusions}

The successful public-private partnership of the university and biotechnology sectors is being threatened by its very success. The cracks we see developing in the system are being papered over by ad hoc solutions that we feel are counterproductive to the health of the research sector, particularly the stem cell field. We believe that better alternatives exist, as exemplified by some of the efforts by universities, non-profits, governments, and companies. Individual investigators should carefully consider the licenses and agreements they sign, so that they are making reasoned choices rather than consigning themselves to unnecessary limitations.

Note: This article is part of a thematic series on Clinical
applications of stem cells edited by Mahendra Rao. Other
articles in the series can be found online at http://stemcellres.
com/series/clinical.

\section{Abbreviations}

CMO: Contract manufacturing organizations; CRISPR: Clustered regularly interspaced short palindromic repeats; CRM: Center for Regenerative Medicine; ESC: Embryonic stem cell; iPSC: Induced pluripotent stem cell; MSC: Mesenchymal stem cell; NIH: National Institutes of Health;

TALEN: Transcription activator-like effector nuclease; ZFN: Zinc finger nuclease.

\section{Competing interests}

The author declares that he has no competing interests.

\section{Acknowledgments}

I would like to acknowledge Steven Becker for preparing the figures and tables and editing the manuscript as well as Megan Laycock for editing and reviewing the manuscript. This work was supported by the National Institutes of Health $(\mathrm{NIH})$ Center for Regenerative Medicine, a Common Fund initiative of the $\mathrm{NIH}$. The opinions expressed in this article represent the personal views of the writer and do not reflect in any way on the stance or policies of his employer.

Published: 14 August 2013

\section{References}

1. Valdivia WD: The stakes in Bayh-Dole: public values beyond the pace of innovation. Minerva 2011, 49:25-46.

2. Webb S: The gold rush for induced pluripotent stem cells. Nat Biotechnol 2009, 27:977-979.

3. Schuldt BM, Guhr A, Lenz M, Kobold S, Macarthur BD, Schuppert A, Loser P, Muller FJ: Power-laws and the use of pluripotent stem cell lines. PLoS One 2013, 8:e52068.

4. Caulfield T, Scott C, Hyun I, Lovell-Badge R, Kato K, Zarzeczny A: Stem cell research policy and iPS cells. Nat Methods 2010, 7:28-33.

5. Phillips BW, Crook JM: Pluripotent human stem cells: a novel tool in drug discovery. BioDrugs 2010, 24:99-108.

6. Georgieva BP, Love JM: Human induced pluripotent stem cells: a review of the US patent landscape. Regen Med 2010, 5:581-591.

7. Mills $A E$, Tereskerz PM: Empirical analysis of major stem cell patent cases: the role of universities. Nat Biotechnol 2010, 28:325-328.

8. Zarzeczny A, Scott C, Hyun I, Bennett J, Chandler J, Chargé S, Heine H, Isasi R, Kato K, Lovell-Badge R, McNagny K, Pei D, Rossant J, Surani A, Taylor PL, Ogbogu U, Caulfield T: iPS cells: mapping the policy issues. Cell 2009, 139:1032-1037.

9. Lowenthal J, Lipnick S, Rao M, Hull SC: Specimen collection for induced pluripotent stem cell research: harmonizing the approach to informed consent. Stem Cells Transl Med 2012, 1:409-421. 
10. Rao MS, Malik N: Assessing iPSC reprogramming methods for their suitability in translational medicine. J Cell Biochem 2012, 113:3061-3068.

11. Courtney A, de Sousa P, George C, Laurie G, Tait J: Balancing open source stem cell science with commercialization. Nat Biotechnol 2011, 29:115-116.

12. Ramos-Mejia V, Montes R, Bueno C, Ayllon V, Real PJ, Rodriguez R, Menendez P: Residual expression of the reprogramming factors prevents differentiation of iPSC generated from human fibroblasts and cord blood CD34+ progenitors. PLoS One 2012, 7:e35824.

13. Isasi $R$, Knoppers BM: From banking to international governance: fostering innovation in stem cell research. Stem Cells Int 2011, 2011:498132.

14. Parsons $X H$, Teng YD, Moore DA, Snyder EY: Patents on technologies of human tissue and organ regeneration from pluripotent human embryonic stem cells. Rec Pat Regen Med 2011, 1:142-163.

15. Perez-Pinera P, Ousterout DG, Gersbach CA: Advances in targeted genome editing. Curr Opin Chem Biol 2012, 16:268-277.

16. Mali P, Yang L, Esvelt KM, Aach J, Guell M, Dicarlo JE, Norville JE, Church GM: RNA-guided human genome engineering via Cas9. Science 2013, 339:823-826.

17. Cong L, Ran FA, Cox D, Lin S, Barretto R, Habib N, Hsu PD, Wu X, Jiang W, Marraffini LA, Zhang F: Multiplex genome engineering using CRISPR/Cas systems. Science 2013, 339:819-823.

doi:10.1186/scrt309

Cite this article as: Rao: LULL(ed) into complacency: a perspective on licenses and stem cell translational science. Stem Cell Research \& Therapy 2013 4:98. 